\title{
Estenosis de la unión pieloureteral
}

\author{
V. Menéndez López, C. Carro Rubias, L. de Paz Cruz, D. García Serrano, F. García López
}

Servicio de Urología. Hospital General Universitario de Elche. Elche. Alicante

$\mathrm{V}$ arón de 24 años diagnosticado de estenosis de la unión pieloureteral mediante ecografía y urografia, confirmada mediante renograma isotópico con diuréticos. Se realiza angio TAC que descarta la presencia de vaso polar (Fig. 1). Ante la imposibilidad de cateterización ureteral retrógrada, se optó por la cirugía abierta, evidenciando como causa de la estenosis un vaso polar no detectado en el TAC (Fig. 2).

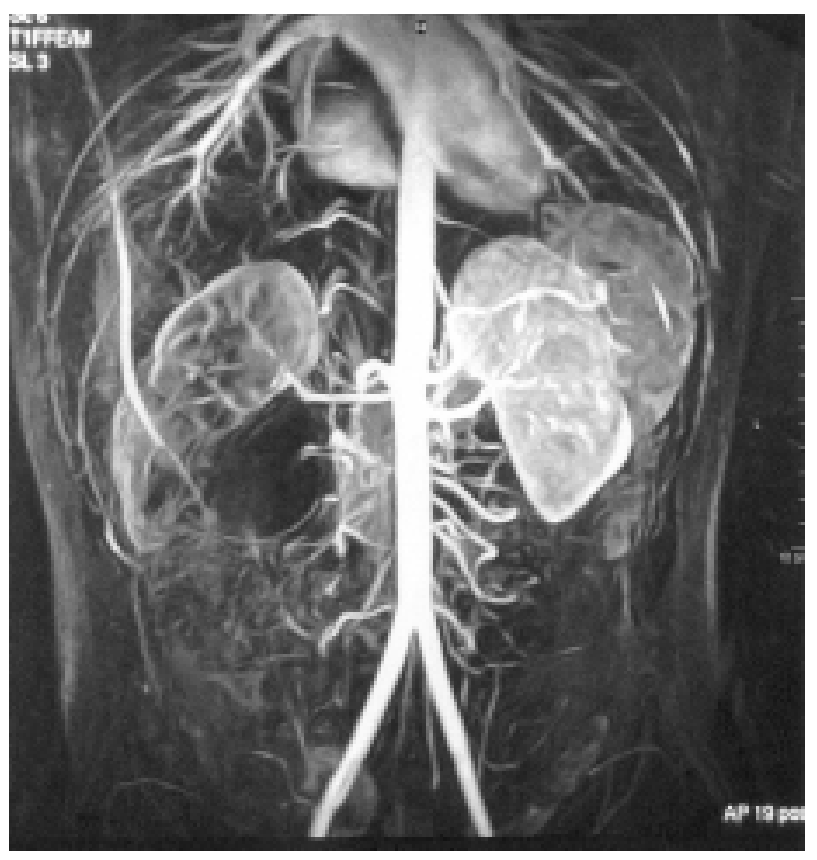

FIGURA 1
Dra. V. Menéndez López

Servicio de Urología

Hospital Universitario de Elche

Partida Huertos y Molinos, s/n

03203 Elche (Alicante)

E-mail: violetamenendez@wanadoo.es

(Trabajo recibido el 17 de julio 2005)

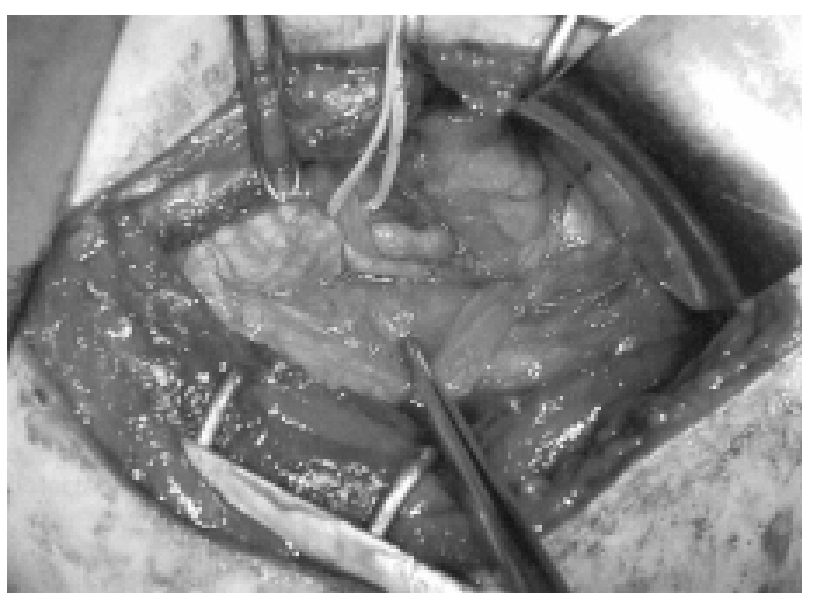

FIGURA 2 